Original

\title{
Feasibility of including APF gel application in a school oral health promotion program as a caries-preventive agent: a community intervention trial
}

\author{
Neha Agrawal and Krishnappa Pushpanjali \\ Department of Public Health Dentistry, M. S. Ramaiah Dental College and Hospital, Bangalore, India
}

(Received 11 November 2010 and accepted 7 March 2011)

\begin{abstract}
A community intervention trial was conducted to assess the feasibility of APF gel as a caries-preventive agent in a high-risk group of school children in Bangalore City. The study was conducted in two schools, randomly selected from a list of schools catering to underprivileged children. These schools were randomly allocated into experimental and control groups. Children aged 9-16 years having three or more incipient or cavitated primary or secondary carious lesions were enrolled in the study. In the experimental group, APF gel was applied and oral health education was provided to both groups at baseline and 6 months. Follow-up examination was performed at 6 and 12 months and the caries status was recorded by an investigator who was blinded to the allocation of intervention. There was no statistically significant difference in DMFT and DMFS values, but a significant difference was seen in incipient carious lesions between the experimental and control groups at 6 and 12 months. These results suggest that biannual APF gel application is an effective preventive measure in reversing incipient carious lesions. (J Oral Sci 53, 185-191, 2011)
\end{abstract}

Keywords: APF gel; caries prevention; enamel remineralization; incipient lesion.

Correspondence to Dr. Neha Agrawal, Department of Public Health Dentistry, M. S. Ramaiah Dental College and Hospital, M. S. R. Nagar, M. S. R. I. T. Post, Bangalore - 560054, Karnataka, India

Tel: +91-9916656746

Fax: +91-5943-263077

E-mail: dr.n_agrawal@yahoo.co.in

\section{Introduction}

Despite great advancement in oral health globally, the problem of dental caries remains in many communities around the world, particularly among socially and economically deprived groups in developed and developing countries (1). Poor children have five times more untreated dental caries (cavities) than children from higher-income families. These dental problems result in pain, infection, and lost school days and work days each year (2).

Historically, caries was thought to be a progressive disease that eventually destroys the tooth unless the dentist intervenes surgically. However, the understanding of caries has changed markedly and this change needs to be reflected in practice. In 2001, a National Institute of Health (NIH) Consensus Statement recognized a paradigm shift in the management of caries. A document developed at the conference entitled "Diagnosis and Management of Dental Caries Throughout Life" identified a transition towards improved diagnosis of non-cavitated, incipient lesions and treatment for prevention and arrest of such lesions (3). Preventive strategies against dental caries targeting school children will go a long way to decrease the future burden of the disease and will improve the oral and general health of individuals and the population.

Fluoride has been the cornerstone of preventive programs worldwide. The American Dental Association (ADA) council on scientific affairs commented that periodic fluoride treatment should be considered for both children and adults who are at moderate or high risk of developing caries (4). Strong evidence exists for the effectiveness of acidulated phosphate fluoride (APF) gel as a cariespreventive agent, but its feasibility at the community level has not been widely evaluated in India. Thus, the present 
study was undertaken to assess the feasibility of application of APF gel as a caries-preventive agent in a high-risk group of school children in Bangalore City, India.

\section{Study participants}

Materials and Methods

The present community interventional trial was conducted from October 2008 to February 2010 in 9- to 16-year-old children belonging to lower socioeconomic status in Bangalore City. No organized oral health care programs for children were available in the schools.

The children were recruited from two schools catering to the underprivileged. These schools were randomly selected from the list of schools in Bangalore. Children eligible for this study were those with good overall health, but with high risk for caries and having three or more incipient or cavitated primary or secondary carious lesions. Children wearing orthodontic bands and presenting with white lesions such as developmental white spots, hypocalcification of enamel or questionable lesions were excluded. Children who were on antibiotic therapy or were using antibacterial mouth rinses for a period of 3 months preceding the study were also excluded. A total of 257 children (130 and 127 children) from Chrystal House and Shishu Mandir School participated in the study. The schools were randomly assigned to an APF gel group (experimental group; Chrystal House) $(n=130)$ and a control group (Shishu Mandir School) $(n=127)$ by coin tossing. The mean age of subjects in the experimental and control groups was 12.83 and 12.94 , respectively. In the experimental group, $51.7 \%$ were males and $48.3 \%$ were females; in the control group, $54.6 \%$ were males and $45.4 \%$ were females. This study was approved by the Ethics Committee of M. S. Ramaiah Dental College and Hospital, Bangalore. Necessary permission was obtained from the school authorities after informing them the nature and protocol of the study. The parents were sent a letter explaining the purpose and procedure of the study with an informed consent form to be duly signed and returned.

\section{Caries diagnostic criteria and examination}

All the examinations were performed in a well-equipped mobile van by two independently calibrated dentists (investigators) $($ Kappa statistic $=0.9)$. Data collection was done with the help of a predesigned semi-structured questionnaire containing demographic information and details of oral hygiene practices. The sources of fluoride available to the children were evaluated and few of them were regularly using fluoridated dentifrice.

Children from each of the classes were assembled and briefed about the procedures they would undergo. On each scheduled day, 20-30 children were examined and 810 minutes were spent for the examination of each subject.

The caries experience of the children was recorded using Decayed, Missing, Filled Teeth (DMFT) and Decayed, Missing, Filled Surfaces (DMFS) indices based on the World Health Organization (WHO) criteria (5). Incipient Lesion (IL) measurement was based on criteria given by Nyvad and colleagues (6). Active enamel lesions were considered as decayed and inactive enamel lesions were considered as sound. Sites were defined as occlusal, buccal and lingual surfaces.

After drying the tooth surface with compressed air, the first investigator performed a visual examination, and if in doubt, used the tip of the explorer to gently check for the loss of surface smoothness or the loss of tooth structure, taking care not to disturb the integrity of the tooth surface. All teeth whose occlusal surfaces were visible were considered for evaluation. Subsequently, the children were classified into high, medium and low caries risk groups based on the criteria given by the ADA and only the high caries risk group was included in the study (4). In the experimental group (Chrystal House School), APF gel application was performed by the second investigator. The control group (Shishu Mandir School) did not receive any intervention. Both the groups received oral health education at baseline. In the experimental group, subjects received topical application of $1.23 \%$ APF gel (Fluorovil, Vishal Dentocare Pvt. Ltd., Ahmedabad, India) at baseline and at 6 months. Both the applications were done in the mobile dental van. After cotton roll isolation, the investigator dried the teeth with compressed air and APF gel was applied in properly selected flexible disposable trays and retained for 4 minutes. Children were asked to bend their head forward during the application period. A clinician (house-surgeon) was appointed for monitoring the child and wiping saliva. Excess gel was wiped off with gauze following tray removal. Children were allowed to expectorate thoroughly on completion of the procedure. They were advised not to eat, drink, or rinse at least for 30 minutes and were instructed to brush their teeth only the next morning. Teachers were asked to check if the children were adhering to the post-intervention instructions.

\section{Follow-up}

Follow-up examinations were done at 6 and 12 months for recording the caries status by the first investigator, who was blinded to the allocation of intervention. The number of inactive lesions was counted and percentage was calculated for each surface. 
Table 1 Caries prevalence (DMFT and DMFS and IL)* in APF gel and control group at baseline, 6 months and 12 months

\begin{tabular}{llll}
\hline & $\begin{array}{l}\text { School 1 } \\
\text { Mean (SD), } n 1=120\end{array}$ & $\begin{array}{l}\text { School 2 } \\
\text { Mean (SD), } n 2=119\end{array}$ & $P^{* *}$ value \\
\hline DMFS 1 & $4.01(1.668)$ & $4.30(1.613)$ & .106 \\
DMFT 1 & $3.16(1.257)$ & $3.22(1.229)$ & .709 \\
IL1 & $5.04(1.951)$ & $4.93(1.903)$ & .663 \\
DMFS 2 & $4.15(1.713)$ & $4.45(1.500)$ & .146 \\
DMFT2 & $3.28(1.403)$ & $3.45(1.494)$ & .364 \\
IL2 & $3.23(1.221)$ & $4.36(1.765)$ & .000 \\
DMFS3 & $4.32(1.439)$ & $4.63(1.484)$ & .108 \\
DMFT3 & $3.40(1.469)$ & $3.66(1.318)$ & .158 \\
IL 3 & $1.18(1.18)$ & $3.03(1.324)$ & .000 \\
\hline$*$ DMFT: decayed, missing and filled teeth, DMFS: decayed, missing and filled surface, \\
IL: incipient lesions \\
1: at base line, 2: at 6 months, 3: at 12 months \\
SD: standard deviation \\
$P^{* *}$ value $<0.05:$ significant, $P^{* *}$ value $>0.05:$ not significant \\
School 1 = Chrystal House School, School 2 = Sishumandir School
\end{tabular}

Table 2A Results of repeated measure of variance (ANOVA) comparing Mean DMFT with in groups at base line, 6 months and 12 months

\begin{tabular}{lllllll}
\hline School & $\begin{array}{l}\text { DMFT 1 } \\
\text { Mean (SD) }\end{array}$ & $\begin{array}{l}\text { DMFT 2 } \\
\text { Mean (SD) }\end{array}$ & $\begin{array}{l}\text { DMFT 3 } \\
\text { Mean (SD) }\end{array}$ & Df & F value & $P$ value \\
\hline $\begin{array}{l}\text { School 1 } \\
(n 1=120)\end{array}$ & $3.16(1.257)$ & $3.28(1.403)$ & $3.40(1.469)$ & 1 & 5.635 & 0.019 \\
$\begin{array}{l}\text { School 2 } \\
(n 2=119)\end{array}$ & $3.22(1.229)$ & $3.45(1.494)$ & $3.66(1.318)$ & 1 & 9.399 & 0.003 \\
\hline
\end{tabular}

Table 2C Results of repeated measure of variance (ANOVA) comparing Mean IL with in groups at base line, 6 months and 12 months

\begin{tabular}{lllllll}
\hline School & $\begin{array}{l}\text { IL 1 } \\
\text { Mean (SD) }\end{array}$ & $\begin{array}{l}\text { IL 2 } \\
\text { Mean (SD) }\end{array}$ & $\begin{array}{l}\text { IL 3 } \\
\text { Mean (SD) }\end{array}$ & Df & F value & $P$ value \\
\hline $\begin{array}{l}\text { School 1 } \\
(n 1=120)\end{array}$ & $5.04(1.951)$ & $3.23(1.221)$ & $1.18(1.18)$ & 1 & 345.89 & 0.000 \\
$\begin{array}{l}\text { School 2 } \\
(n 2=119)\end{array}$ & $4.93(1.903)$ & $4.36(1.765)$ & $3.03(1.324)$ & 1 & 95.688 & 0.000 \\
\hline
\end{tabular}

\section{Statistical analysis}

Data were analyzed using SPSS (Statistical Package for Social Sciences) version 16. Student's $t$-test was used to determine the difference in DMFT, DMFS and IL between the two groups. Repeated Measure of Analysis of Variance (ANOVA) was used to find out the difference within each group at follow up period compared to baseline with respect to DMFT, DMFS and IL. The significance level was defined as $P<0.05$.

\section{Results}

There were no significant differences in baseline characteristics among the groups.
Table 2B Results of repeated measure of variance (ANOVA) comparing Mean DMFS with in groups at baseline, 6 months and 12 months

\begin{tabular}{lllllll}
\hline School & $\begin{array}{l}\text { DMFS 1 } \\
\text { Mean (SD) }\end{array}$ & $\begin{array}{l}\text { DMFS 2 } \\
\text { Mean (SD) }\end{array}$ & $\begin{array}{l}\text { DMFS 3 } \\
\text { Mean (SD) }\end{array}$ & Df & F value & $P$ value \\
\hline $\begin{array}{l}\text { School 1 } \\
(n 1=120)\end{array}$ & $4.01(1.668)$ & $4.15(1.713)$ & $4.33(1.439)$ & 1 & 7.021 & 0.009 \\
$\begin{array}{l}\text { School 2 } \\
(n 2=119)\end{array}$ & $4.30(1.613)$ & $4.45(1.500)$ & $4.63(1.484)$ & 1 & 2.521 & 0.005 \\
\hline
\end{tabular}

Table 1 shows baseline data and changes in caries prevalence. No statistically significant difference was found in DMFT and DMFS between the experimental and control groups at baseline, 6 months and 12 months. However, a significant difference was seen in IL values at 6 months and 12 months between the experimental and control groups.

Table 2A, 2B and 2C show the results of analysis of Repeated Measure of Variance (ANOVA). Statistically significant difference was found in the mean DMFS, DMFT and IL values at 6 months and 12 months within experimental and control groups from baseline (Figs. 1, 2 and 3 ).

As shown in Table 3 (Fig. 4), 366 (60.5\%) of 604 active enamel lesions were on the occlusal surface in the experimental group, while $449(76.5 \%)$ of 585 active enamel lesions were on the occlusal surface in the control group. In the experimental group, $76.50 \%$ percent of active enamel lesions became inactive after 12 months, compared with $35.8 \%$ percent of active enamel lesions in the control group.

Out of the 604 active enamel lesions, 154 (25.5\%) were on the buccal surface in the experimental group, while 70 


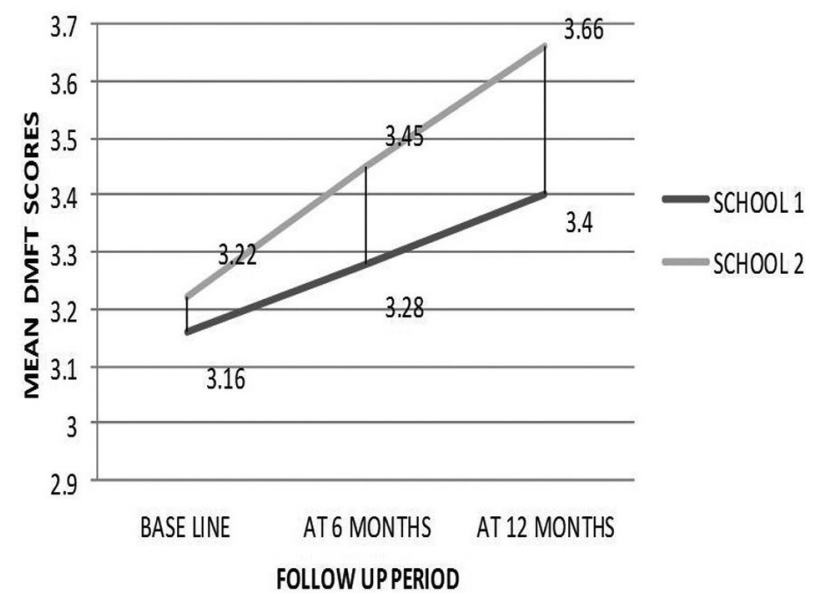

Fig. 1 Mean DMFT scores at baseline, 6 months and 12 months in 2 study groups.

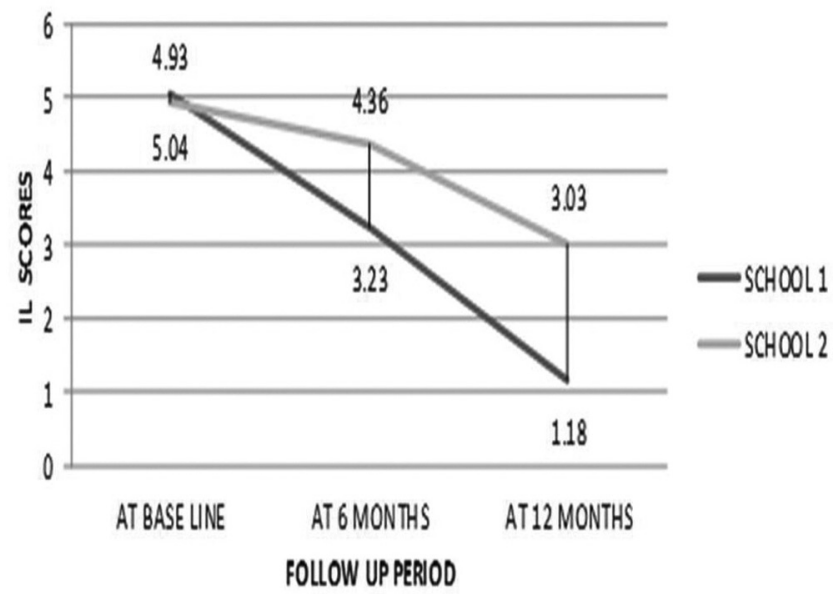

Fig. 3 Mean IL scores at baseline, 6 months and 12 months in 2 study groups.

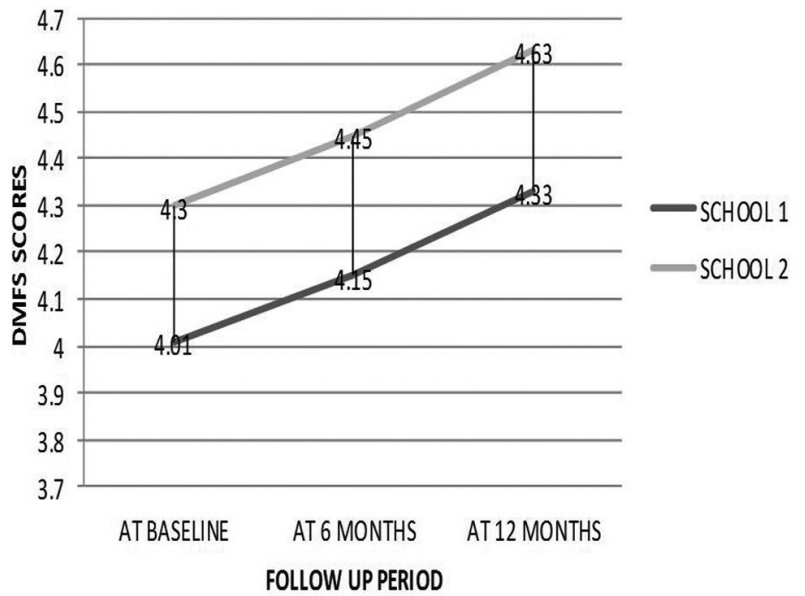

Fig. 2 Mean DMFS scores at baseline, 6 months and 12 months in 2 study groups.

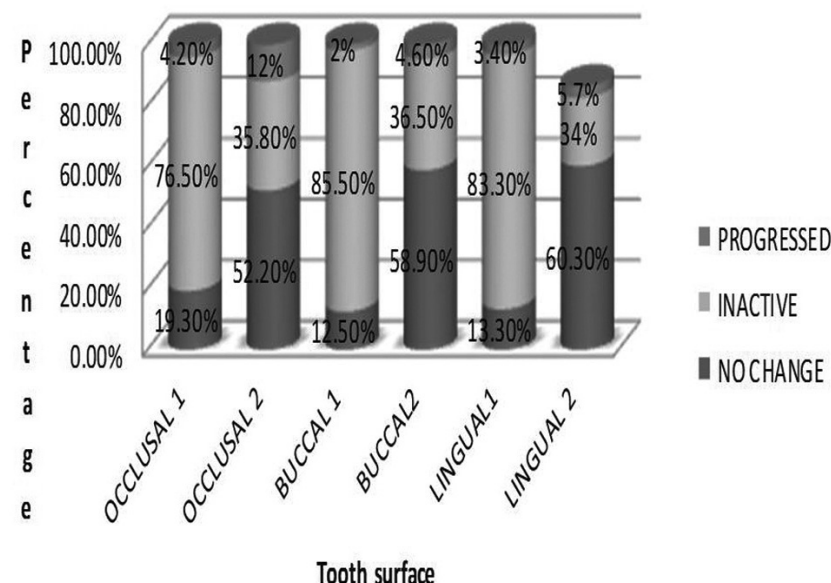

Fig. 4 Distribution of incipient carious lesion at 12 months in school 1 and 2.

Table 3 Distribution of incipient enamel lesions at 12 months

\begin{tabular}{|c|c|c|c|c|c|}
\hline \multirow{2}{*}{$\begin{array}{l}\text { Tooth } \\
\text { surface }\end{array}$} & \multirow[t]{2}{*}{ Group } & \multicolumn{4}{|c|}{ Number $(\%)$ of active lesions } \\
\hline & & $\begin{array}{l}\text { No change } \\
\text { Number (\%) }\end{array}$ & $\begin{array}{l}\text { Inactive } \\
\text { Number (\%) }\end{array}$ & $\begin{array}{l}\text { Progressed } \\
\text { Number (\%) }\end{array}$ & $\begin{array}{l}\text { Total } \\
\text { Number (\%) }\end{array}$ \\
\hline \multirow[t]{2}{*}{ Occlusal } & APF gel & $70(19.3 \%)$ & $280(76.5 \%)$ & $16(4.2 \%)$ & $366(60.5 \%)$ \\
\hline & Control & $234(52.2 \%)$ & $161(35.8 \%)$ & $54(12 \%)$ & $449(76.5 \%)$ \\
\hline \multirow[t]{2}{*}{ Buccal } & APF gel & $19(12.5 \%)$ & $132(85.5 \%)$ & $3(2 \%)$ & $154(25.5 \%)$ \\
\hline & Control & $42(58.9 \%)$ & $25(36.5 \%)$ & $3(4.6 \%)$ & $70(12.3 \%)$ \\
\hline \multirow[t]{2}{*}{ Lingual } & APF gel & $11(13.3 \%)$ & $71(83.3 \%)$ & $2(3.4 \%)$ & $84(14 \%)$ \\
\hline & Control & $40(60.3 \%)$ & $22(34 \%)$ & $4(5.7 \%)$ & $66(11.2 \%)$ \\
\hline \multirow[t]{2}{*}{ Total } & APF gel & $100(16.7 \%)$ & $483(79.70 \%)$ & $21(3.52 \%)$ & $604(100 \%)$ \\
\hline & Control & $316(53.6 \%)$ & $208(35.5 \%)$ & $61(10.34 \%)$ & $585(100 \%)$ \\
\hline
\end{tabular}

$(12.3 \%)$ of 585 active enamel lesions were on the buccal surface in the control group. In the experimental group,
$85.5 \%$ percent of active enamel lesions became inactive after 12 months, compared with $36.5 \%$ percent of active 
enamel lesions in the control group.

Eighty-four (14\%) of 604 active enamel lesions were on the lingual surface in the experimental group, while 66 (11.2\%) of 585 active enamel lesions were on the lingual surface in the control group. In the experimental group, $83.3 \%$ percent of active enamel lesions became inactive after 12 months, compared with $34 \%$ percent of active enamel lesions in the control group.

\section{Discussion}

The prevention of dental caries in children and adolescents is generally regarded as a priority for dental services and is considered more cost effective than treatment. Fluoride therapy has been the cornerstone of caries prevention strategies since the introduction of the water fluoridation scheme over five decades ago (7). The need of the hour is to develop scientifically sound, fieldbased prevention-oriented oral health strategies to tackle this ever-accumulating burden of dental caries in the underprivileged population of developing countries. To the best of our knowledge, the present study is the first community intervention trial that has demonstrated the feasibility of APF gel application as a caries-preventive agent among high-risk school children in Bangalore, India.

In the study, communities selected for the trial were similar with respect to socioeconomic status (both belonged to private funded schools catering to underprivileged children). The schools were randomized into experimental and control groups. Our intention was to enhance the application of evidence and to minimize contamination, as the unit of randomization and analysis was schools. Very often blinding is not possible in this type of studies. The problem of contamination and co-intervention was eliminated as the communities were located at arge distance from each other and no other intervention was ongoing in either school during the study period. An inherent drawback of the study design adopted was the 'school effect' due to clustering of subjects, which could not be eliminated.

It is widely accepted that children at high risk of developing caries need extra protection and often are not compliant enough to undertake fluoride therapy themselves (8). The present study supports the proposal that gel application may be a practical preventive treatment that can be performed in school environment, which would allow more high risk children to be accessed. This is in accordance with other studies $(9,10)$.

In the present study, the attrition rate was $7 \%$. The main reason for children to drop out of the study included families moving from the area, resulting in children withdrawing from the school program.
The mean age of children in the experimental and control groups was 12.83 and 12.94, respectively, which conforms to one of the WHO index age groups and is considered as Global Monitoring Age (5).

Nyvad and colleagues described caries diagnostic criteria that differentiate between active and inactive carious lesions at both cavitated and non-cavitated sites in permanent dentition. They concluded that the use of criteria based on an activity assessment could be highly reliable when non-cavitated lesions are included in the scoring system (6). Therefore, this index was found to be suitable for a community-based study as the criteria used were well defined.

The present study showed no statistically significant difference in mean DMFT, DMFS and IL scores of participating children between the experimental and control groups at baseline. This signifies relatively equal distribution of DMFT, DMFS and IL scores between the two groups at baseline. Even at 6 and 12 months, there was no statistically significant difference in mean DMFT and DMFS values between the experimental and control groups, because the mean time required for a carious lesion to progress through the enamel is 3-5 years (11-13). At 6 months, a statistically significant difference was found in mean IL scores between the experimental and control groups. At 12 months, a significant difference was found in IL values between the experimental and control groups. This decrease is primarily on account of re-mineralization of active non-cavitated incipient carious lesions, thus suggesting the ability of APF gel to remineralize the incipient carious lesions. Due to the lack of previous studies pertaining to the effect of APF gel on incipient carious lesions, the present results could not be correlated.

A statistically significant difference was found in the mean DMFS and DMFT values from baseline to 6 months and from baseline to 12 months within the experimental and control groups. This could be because few of the incipient carious lesions progressed to cavitation due to factors that were not under the control of the investigator, such as poor oral hygiene, food habits and biological variations. However, its clinical value and public health impact needs to be critically assessed by conducting the same type of study in a larger population.

The percentage of caries reduction in the experimental group was $76.5 \%$ on the occlusal surface, $85.5 \%$ on the buccal surface and $83.3 \%$ on the lingual surface. The percentage of caries reduction in the present study was higher than in other studies (14-18) and the results obtained from various reviews and meta-analysis (19-21). This could be attributed to the fact that in all the above studies and reviews, incipient lesions were not recorded. Therefore, 
part of the variability in APF gel studies in regard to reducing the caries increments is associated with the diagnostic criteria used.

In this study, the amount of APF gel used to cover upper and lower teeth was approximately $2.5 \mathrm{ml}$, which was smaller than the single dose required for acute poisoning (1 mg fluoride/kg body weight). Also, precautions were taken in this study such as using well-fitting trays, seating the child upright with the head inclined forward and downward and instructing the child to expectorate saliva for 1 minute after tray removal. Along with this, an investigator was appointed for monitoring the child and wiping off the drooling saliva during the procedure. No clinical side-effects were reported after APF gel application in the study. This suggests that APF gel application is a relatively safe and feasible caries-preventive therapy in community programs, if the recommended guidelines are strictly followed.

The study was conducted as part of an ongoing oral health promotion program in these two institutions and the children from both the schools are being provided adequate dental care by our institution.

This study suggests that APF gel offers an effective means of re-mineralizing and arresting incipient carious lesions in permanent dentition. This therapy can be performed in a school environment, which would allow more access to high-risk children.

\section{References}

1. Petersen PE (2003) The world oral health report: continuous improvement of oral health in the $21 \mathrm{st}$ century - the approach of the WHO global oral health programme. Community Dent Oral Epidemiol 31, Suppl s1, 3-24.

2. United States General Accounting Office (2000) Oral health: dental disease is a chronic problem among low income population. available online at $\mathrm{http}: / /$ docs.google.com/viewer?a=v\&q=cache:YnLA x8JHx4UJ:www.gao.gov/new.items/he00072.pdf

3. Edelstein BL (2006) The dental caries pandemic and disparities problem. BMC Oral Health 6, Suppl 1, S2

4. American Dental Association Council on Scientific Affairs (2006) Professionally applied topical fluoride: evidence-based clinical recommendations. J Am Dent Assoc 137, 1151-1159.

5. World Health Organization (1997) Oral health surveys: basic methods. 4th ed, WHO, Geneva.

6. Nyvad B, Machiulskiene V, Baelum V (1999) Reliability of new caries diagnostic system differentiating between active and inactive caries lesions. Caries Res 33, 252-260.

7. Marinho VCC, Higgins JPT, Logan S, Sheiham A (2003) Fluoride mouthrinses for preventing dental caries in children and adolescents. Cochrane Database of Systematic Reviews 3, Art. No.: CD002284. DOI: 10.1002/14651858.CD002284.

8. Autio-Gold JT, Courts F (2001) Assessing the effect of fluoride varnish on early enamel carious lesions in the primary dentition. J Am Dent Assoc 132, 1247-1253.

9. Olivier M, Brodeur JM, Simard PL (1992) Efficacy of APF treatments without prior toothcleaning targeted to high-risk children. Community Dent Oral Epidemiol 20, 38-42.

10. Johnston DW, Lewis DW (1995) Three-year randomized trial of professionally applied topical fluoride gel comparing annual and biannual application with/without prior prophylaxis. Caries Res 29, 331-336.

11. Pitts NB (1983) Monitoring of caries progression in permanent and primary posterior approximal enamel by bitewing radiography. Community Dent Oral Epidemiol 11, 228-235.

12. Gustafsson A, Svenson B, Edblad E, Jansson L (2000) Progression rate of approximal carious lesions in Swedish teenagers and the correlation between caries experience and radiographic behavior. An analysis of the survival rate of approximal caries lesions. Acta Odontol Scand 58, 195-200.

13. Mejàre I, Källestål C, Stenlund H, Johansson H (1998) Caries development from 11 to 22 years of age: a prospective radiographic study. Prevalence and distribution. Caries Res 32, 10-16.

14. Seppä L, Leppänen T, Hausen H (1995) Fluoride varnish versus acidulated phosphate fluoride gel: a 3-year clinical trial. Caries Res 29, 327-330.

15. Horowitz HS, Doyle J (1971) The effect on dental caries of topically applied acidulated phosphate fluoride: results after three years. J Am Dent Assoc 82, 359-365.

16. Horowitz HS, Kau MC (1974) Retained anticaries protection from topically applied acidulated phosphate fluoride: 30 - and 36-month post-treatment effects. J Prev Dent 1, 22-27.

17. Bryan ET, Williams JE (1968) The cariostatic effectiveness of a phosphate-fluoride gel administered annually to school children. I. The results of the first year. J Public Health Dent 28, 182185.

18. Bryan ET, Williams JE (1970) The cariostatic effectiveness of a phosphate-fluoride gel 
administered annually to school children: final results. J Public Health Dent 30, 13-16.

19. Marinho VC, Higgins JP, Logan S, Sheiham A (2003) Systematic review of controlled trials on the effectiveness of fluoride gels for the prevention of dental caries in children. J Dent Educ 67, 448-458.
20. Van Rijkom HM, Truin GJ, Van't Hof MA (1998) A meta-analysis of clinical studies on the cariesinhibiting effect of fluoride gel treatment. Caries Res 32, 83-92.

21. Weintraub JA (2002) Fluoride gel applications reduce caries incidence. Evid Based Dent 3, 64-65. 